\title{
Pengaruh Iklim Kelas Terhadap Resiliensi Akademik, Mastery Goal Orientation dan Prestasi Belajar
}

\author{
Raja Oloan Tumanggor dan Agoes Dariyo \\ Fakultas Psikologi Universitas Tarumanagara Jakarta \\ lusoloania@gmail.com; agoesdariyo@gmail.com
}

\begin{abstract}
This study analyzes the extent to which the influence of the classroom climate on academic resilience, Mastery Goal Orientation (MGO) and learning achievement. Classroom climate is a psychosocial atmosphere created through the interaction between lecturers and students during the learning process in the classroom. Good classroom climate is created through dynamic collaboration through social interaction between faculty and students. While academic resilience is someone toughness in the face of a variety of academic tasks in the educational environment. A student whose academic resiliens will not be easy to despair in the face of academic difficulties. While MGO is a part of the motivation that encourages a student to master the course material, so that he was able to complete the task with good lectures. The results of a student learning achievement called learning achievement. Be a reflection of the learning achievement of learning outcomes in a given period of time. From a study of 90 students of a private university in Jakarta, the results showed that the first, classroom climate has a significant influence on academic resilience and MGO. Secondly, there is the effect of MGO on academic resilience. Third, classroom climate, academic resilience, and MGO did not have a significant effect on learning achievement.
\end{abstract}

Key words: classroom climate, academic resilience, mastery goal orientation, learning achievement.

\section{Latar Belakang}

Prestasi belajar adalah suatu hasil pencapaian seorang peserta didik setelah menempuh suatu ujian yang diberikan oleh guru atau dosen di lembaga pendidikan (Dariyo, 2012). Selain faktor internal, prestasi belajar dipengaruhi juga oleh faktor eksternal. Salah satu faktor eksternal ialah iklim lingkungan kelas, yaitu suasana psikososial yang berkembang dalam proses belajar-mengajar di kelas (Gentry, Gable, \& Rizza, 2002) . Iklim kelas tercipta melalui proses interaksi sosial antara individu dengan individu yang lain dalam lingkungan kelas. Peran pendidik (guru/dosen) dan peserta didik (siswa/mahasiswa) menyumbangkan terciptanya iklim kelas (Church, Elliot, \& Gable, 2001).

Bila iklim kelas dirasakan positif, maka seorang pendidik (dosen) sebagai ahli pendidikan akan bersemangat untuk menyelenggarakan proses pengajaran dengan sebaik-baiknya (Santrock, 2007; McGregor \& Elliot, 2002). Segala potensi dan kompetensinya dicurahkan untuk mengajar, mendidik dan membina peserta didik. Demikian pula, peserta didik pun akan memperoleh stimulasi positif dari dosen, sehingga mereka bersemangat dalam belajar menguasai materi pengajaran dengan baik (Locke \& Latham, 1990). Menguasai materi pengajaran adalah syarat penting untuk menghadapi berbagai tugas ujian kuliah. Mereka yang mampu menguasai materi pengajaran akan dengan mudah menyelesaikan tugas-tugas kuliah dan ujiannya dengan baik (Harackiewics, Barron, \& Elliot, 2000).

Iklim kelas yang buruk akan mempengaruhi proses belajar-mengajar yang dirasakan oleh dosen maupun mahasiswa. Dosen menjadi tidak bergairah dalam melangsungkan pengajarannya di kelas, akibatnya menjalar pula pada suasana demotivasi mahasiswa yang tidak bersemangat dalam belajarnya (McGregor \& Elliot, 2002). Mahasiswa yang tidak bersemangat dalam belajar, tentu saja tak akan dapat menguasai materi pelajaran, akibatnya diperkirakan mereka tak akan berhasil dalam menghadapi ujiannya. Kalau mereka tak berhasil menyelesaikan ujiannya, maka mereka pun akan memiliki prestasi belajar yang rendah pula (Lapper, Corpus, \& Iyengar, 2005) .

Iklim kelas yang baik tercipta melalui kerjasama yang dinamis melalui interaksi sosial antara dosenmahasiswa. Memang dosen berperan sangat besar dalam menciptakan suasana akademik yang memacu semangat mahasiswa untuk menguasai materi-materi perkuliahan di kelas. Bahkan para mahasiswa tetap bergairah dalam belajar dan memiliki ketangguhan dalam menghadapi berbagai masalah resiliensi akademik (academic resilience) (Mason, \& Bramble, 1997). Mereka tak akan mudah putus asa ketika mereka 
menemui kesulitan akademik. Setiap kesulitan akademik diyakini oleh mahasiswa dapat diselesaikan dengan sebaik-baiknya (Bandura, 2007). Jadi iklim kelas yang baik mampu mendorong terciptanya resiliensi akademik pada diri mahasiswa (Mason \& Bramble, 1997).

Persoalan yang ingin diangkat adalah apakah ada pengaruh iklim kelas terhadap resiliensi/ ketangguhan akademik, mastery goal orientation dan prestasi belajar. Penelitian ini bermanfaat untuk mengembangkan konsep teori psikologi pendidikan terutama konsep teori iklim kelas, resiliensi akademik, mastery goal orientation yang berpengaruh terhadap prestasi belajar mahasiswa. Dengan penerapan Kurikulum Berbasis Kompetensi (KBK) bagi mahasiswa angkatan 2012, maka Fakultas Psikologi Universitas Tarumanagara harus mengubah berbagai norma kegiatan perkuliahan. Para dosen yang terlibat dalam proses pembelajaran harus mampu mengubah gaya mengajar yang baru sesuai dengan tuntutan KBK. Karena itu, seorang dosen harus bekerja sama dengan rekan dosen lainnya dalam mengembangkan iklim kelas. Penelitian ini merupakan langkah awal untuk mengetahui bagaimana proses pengembangan iklim kelas yang berpengaruh terhadap mastery goal orientation, resiliensi akademik dan prestasi belajar pada mahasiswa. Hasil penelitian ini bisa dijadikan bahan dasar evaluasi untuk pengembangan iklim kelas yang didasarkan pada pembelajaran dengan basis KBK maupun Kurikulum Sistem Kredit Semester (SKS).

\section{Tinjauan Pustaka}

Prestasi belajar ialah hasil pencapaian belajar dari seorang mahasiswa yang telah menghadapi berbagai tugas akademik di lingkungan perguruan tinggi. Prestasi belajar merupakan cerminan hasil pembelajaran yang dilakukan oleh seorang mahasiswa dalam jangka waktu tertentu (Arbona, 2000). Hasil kerja keras yang dilakukan oleh mahasiswa dituangkan dalam laporan hasil studi. Setiap dosen yang telah mengajar mahasiswa tersebut, berusaha untuk memberikan evaluasi dan penilaian akademik atas usaha belajar mahasiswa yang bersangkutan.

Secara umum, prestasi belajar dipengaruhi oleh 2 faktor yaitu faktor internal dan faktor eksternal (Santrock, 2007). Faktor internal ialah segala kondisi fisiologis dan psikologis yang dirasakan oleh seorang mahasiswa. Kondisi fisiologis antara lain: kesehatan fisik. Kondisi psikologis antara lain: kecerdasan, minat, bakat, kreativitas, motivasi, dan sebagainya. Faktor eksternal ialah segala sesuatu yang berada di luar jangkauan individu, seperti: lingkungan kelas (sekolah atau kampus), budaya lingkungan kampus, norma-norma dan aturan sosial sekolah, dan sebagainya (Dariyo, 2012).

Iklim kelas ialah suasana psikososial yang tercipta melalui interaksi antara dosen dengan mahasiswa selama proses belajar mengajar di kelas (Ames, 1992). Interaksi sosial dosen-mahasiswa mampu menciptakan suasana yang memberi pengaruh terhadap proses belajar dan mengajar (Church, Elliot, \& Gable, 2001). Seorang dosen berperan besar menciptakan suasana akademik yang kondusif, bila ia mampu menguasai lingkungan kelas (Ames, 1992; Church at al, 2001).

Seorang dosen haruslah memahami dan mampu bagaimana menciptakan iklim kelas yang positif (Parkay, \& Stanford, 1995). Kemampuan menciptakan iklim kelas harus dimulai dari kesadaran diri agar seorang dosen mampu menyampaikan pengajarannya secara efektif di kelas (Santrock, 2007). Ketika seorang dosen mampu mendorong terciptanya iklim kelas positif, maka para mahasiswa pun akan memperoleh pengaruh positif dari semangat dosen dalam mengajar, membimbing dan membina para mahasiswanya (Finn, Garber \& Boyd-Zaharias, 2005; Gentry, Gable, \& Rizza, 2002).

Mastery goal orientation ialah suatu bagian motivasi yang mendorong seorang mahasiswa untuk menguasai materi perkuliahan sehingga ia mampu menyelesaikan suatu tugas perkuliahan dengan baik (McGregor \& Elliot, 2002; Harackiewics, Barron, Pintrich, Elliot, \& Thrash, 2002; Elliot, 2005). Tipe orang yang memiliki orientasi menguasai materi perkuliahan, menyadari bahwa keberhasilan dalam meraih suatu cita-cita pendidikan, sangat ditentukan oleh kemampuan menguasai ketrampilan akademik (Harackiewics, Barron, Tauer, \& Elliot, 2002; Lapper, M. R, Corpus, J. H \& Iyengar, S. I., 2005). Apabila ia dapat menguasai berbagai materi perkuliahan dengan baik, maka ia merasa yakin dapat menghadapi tugas-tugas perkuliahan dengan baik pula (Hamachek,1990).

Karena itu, seorang mahasiswa yang memiliki orientasi menguasai materi perkuliahan, ditandai dengan jenis motivasi internal yang tumbuh atas kesadaran diri-sendiri (Harackiewics, Barron, \& Elliot, 2000). Namun adakalanya, munculnya kesadaran diri sendiri tersebut berkaitan dengan stimulasi lingkungan eksternal yang positif, misalnya iklim lingkungan kelas (Church at al, 2001). Bila iklim lingkungan kelas bersifat positif, maka seseorang mahasiswa semakin terpacu pula untuk belajar rajin, giat dan sungguh-sungguh dalam menguasai pelajaran (Hamachek, 1990). 
Resiliensi akademik ialah ketangguhan seseorang dalam menghadapi berbagai tugas akademik dalam lingkungan pendidikan (Corsini, 2002). Seorang mahasiswa yang resilien secara akademik, tak akan mudah putus asa dalam menghadapi kesulitan akademik. Ia akan merasa optimis dan berpikir positif, meskipun ia sedang berada dalam suatu kesulitan akademik. Ia percaya bahwa ada jalan keluar (solusi) (Bandura, 1997; Chemers, Hu, \& Garcia, 2001). Ia juga merasa tertantang untuk memecahkan berbagai kesulitan akademik tersebut. Berbagai kesulitan tersebut mendorong seseorang untuk mengerahkan segenap potensi agar semakin berkembang kompetensinya.

Berbagai kesulitan akademik yang dihadapi oleh seorang mahasiswa merupakan tantangan yang memacu pengembangan potensinya. Seorang mahasiswa yang memiliki resiliensi akademik yang tinggi, justru menyukai tantangan demi tantangan, karena hal itu merupakan kesempatan terbaik untuk membuktikan diri sebagai seorang pembelajar aktif di perguruan tinggi (Lodewyk, \& Winne, 2005). Seorang mahasiswa memperoleh kesempatan belajar dari situasi yang sulit, menantang dan memacu segenap potensinya. Sebaliknya, mahasiswa yang resiliensinya rendah merasa cemas, takut dan menghindar dari kesulitan, karena hal itu akan mengancam eksistensi dirinya (Hamachek, 1990). Ia tak mau dan berusaha menghindari resiko kesulitan. Akibatnya, ia kadang mudah putus asa dan menyerah, sebelum menghadapi masalahnya.

\section{Metode Penelitian}

Karakteristik Subjek penelitian adalah mahasiswa aktif angkataan 2013/2014 Fakultas Psikologi Universitas Tarumanagara yang mengikuti perkuliahan blok psikologi perkembangan. Populasi mahasiswa aktif di Fakultas Psikologi Untar adalah 962 orang mahasiswa. Mahasiswa angkatan sebelum 2012 (dari $2006-$ 2011) memperoleh kurikulum Sistem Kredit Semester (SKS). Namun bagi mahasiswa angkatan terbaru (2012) telah menerima Kurikulum Berbasis Kompetensi (KBK). Jumlah mahasiswa aktif khusus angkatan 2013 adalah 154 orang. Jumlah mahasiswa tersebut mengikuti mata kuliah blok psikologi perkembangan. Semua subjek diberikan kuesioner, namun data yang bisa dianalisis sejumlah 90 orang. Berbagai alasan yang menyebabkan data tak bisa dianalisis adalah kurang lengkapnya pengisian data kuesioner, atau kuesioner tidak dikembalikan lagi kepada peneliti. Jadi jumlah data subjek yang diperoleh dalam penelitian ini sebanyak 90 orang.

Berdasarkan umur diketahui umur $18(11=12,2 \%)$, umur 19 (68=75,6 \%), umur $20(7=7,8 \%)$, $21(3=3,3 \%), 23(1=1,1 \%)$. Gambaran subjek berdasarkan jenis kelamin jumlah subjek laki-laki $=10($ $11,1 \%)$ dan wanita $=80$ orang $(88,9 \%)$. Diketahui subjek yang bersuku Jawa $(14=15,6 \%)$, Batak $(13=$ $14,4 \%)$, Kalimantan $(2=2,2$,$) , Sunda (7=7,8 \%)$, Betawi $(4=4,4, \%)$, Tionghoa $(44=48,9 \%)$, Minang (1), Nusa Tenggara Tmur $(1=1,1 \%)$, Melayu Riau $(1=1,1 \%)$, Bali $(1=1,1 \%)$, Makasar $(1=1,1 \%)$, Jambi $(1=1,1 \%)$.

Keterlibatan organisasi: mahasiswa yang aktif organisasi $(52=57,8 \%)$ dan tidak aktif organisasi (38 $=42,2 \%)$. Gambaran subjek berdasarkan urut kelahiran yaitu anak pertama $(39=43,3 \%)$, anak tengah $(20=22,2 \%)$ dan anak terakhir $(31=34,4 \%)$. Ayah bekerja sebagai pegawai swasta atau PNS $=46(51,1$ $\%)$ dan ayah wiraswasta $=44(48,9 \%)$. Gambaran pendidikan ayah subjek yaitu Sarjana S2-S3 $(7=7,8$ $\%)$, sarjana/akademi (35 = 38,9 \%), SMA/K (44=48,9\%), SMP ( $1=1,1 \%)$, SD (3=3,3 \%). Pendidikan ibu subjek S2-S3 ( $2=2,2 \%$ ), Sarjana/akademi ( $43=47,8 \%)$, SMA/SMK ( $36=36=40 \%)$, SMP ( $7=7,8 \%$ ), $\mathrm{SD}(2=2,2 \%)$. Gambaran ibu subjek yang bekerja/wiraswasta ( $44=48,9 \%)$ dan tidak bekerja 46 ( $51,1 \%)$.

Penelitian ini menggunakan 4 variabel yaitu 1 variabel bebas dan 3 variabel tergantung. Variabel Bebas: iklim kelas. Variabel tergantung: resiliensi akademik, mastery goal orientation dan prestasi belajar. Bila dibuat variabel operasional maka akan diketahui sebagai berikut: Iklim kelas ialah hasil skor yang diperoleh melalui pengisian angket iklim kelas. Semakin tinggi skor angket iklim kelas, makin baik pula iklim kelas tersebut. Resiliensi akademik ialah hasil skor yang diperoleh melalui pengisian angket resiliensi akademik. Semakin tinggi skor angket resiliensi akademik, makin tinggi pula resiliensi akademiknya. Mastery goal orientation ialah hasil skor yang diperoleh melalui pengisian angket mastery goal orientation. Semakin tinggi skor angket mastery goal orientation, makin tinggi pula mastery goal orientationnya. Prestasi belajar ialah hasil skor nilai yang telah dicapai oleh mahasiswa dan diperoleh melalui hasil belajar mata kuliah psikologi perkembangan. Hasil prestasi diperoleh melalui nilai akhir dari prestasi belajar psikologi perkembangan.

Pengambilan data dilakukan dengan menggunakan alat ukur berupa kuesioner yaitu: iklim kelas, resiliensi akademik, mastery goal orientation. Semua alat ukur disusun oleh peneliti sendiri dan diujico- 
bakan untuk memperoleh reliabilitasnya. Adapun data prestasi belajar mahasiswa diperoleh melalui hasil catatan yang ada di Biro Akademik Universitas Tarumanagara. Alat ukur iklim kelas terdiri dari 18 item, namun setelah dilakukan uji coba (try out) diperoleh item-item yang valid sebanyak 14 item, sedangkan 4 item gugur (tidak valid). Iklim kelas $0,240-0,585$. Butir yang valid yaitu $1=0,528,2=0,445,3=0,240$, $4=0,502,5=0,389,6=0,459,7=0,585,8=0,550,9=0,450,10=.0,467,11=0,425,12=0,355,14=.0$, $311,15=0,292$. Butir-butir yang gugur $=13,16,17,18$. Reliabilitas iklim kelas dengan alpha chronbach sebesar $=0,802$.

Alat ukur MGO terdiri dari 6 item. $1=0, .377,2=0,402,3=0,319,4=0,472,5=0,487$, dan $6=0,370$. Reliabilitas alat ukur MGO alpha chronbach sebesar.0,672. Jadi semua item tergolong reliabel (tidak ada item yang gugur). Alat ukur resiliensi akademik (RA) terdiri dari 18 item. Adapun item-item yang valid memiliki skor validitas bergerak dari angka terkecil $=0,308$ dan angka terbesar $=0,674$. Butir-butir resiliensi akademik yang valid yaitu RA $1=0,437$, RA2 =.0,396, RA4=0,338, RA7=0,364, RA8 = 0,420, RA9=0,308, RA10=0,517, RA11=0,552 RA12 = 0,614, RA13 =.449, RA14 = .612, RA15 =0, 674, RA16=0,650. Rentang validitas alat ukur resiliensi akademik yaitu bergerak dari angka 0,308-0,674. Butir-butir yang tidak valid yaitu RA 3, RA5, RA17, RA18. Jadi melalui uji coba diperoleh 14 item yang valid, sedangkan 4 item dinyatakan gugur atau tidak valid. Reliabilitas alpha chronbach $=0,840$.

Desain penelitian yang dianalisis adalah bagaimana pengaruh iklim kelas terhadap resiliensi akademik dan MGO terhadap prestasi belajar. Analisis data dilakukan dengan menggunakan program SPSS versi 15 dengan teknik analisis korelasi, regresi sederhana dan regresi ganda.

\section{Hasil Penelitian dan Pembahasan}

Menurut Nisfianoor (2013) syarat untuk melakukan uji korelasi adalah dengan memenuhi uji distribusi data yang normal. Artinya data variabel-variabel yang akan diuji harus memenuhi syarat distribusi normal. Ketentuan untuk mengetahui normal tidaknya distribusi data dapat diketahui melalui signifikansi yaitu: $\mathrm{P}>0,05$ distribusi normal dan $\mathrm{P}<0,005$ distribusi tidak normal. Diketahui bahwa signifikansi $(\mathrm{P})$ $=0,595>0,05$, artinya distribusi data adalah normal. Dengan demikian data iklim kelas dan prestasi belajar bisa digunakan untuk uji korelasi. Uji normalitas distribusi data iklim kelas dan MGO diketahui bahwa signifikansi $\mathrm{P}=0,014<0,05$ artinya distribusi normal. Uji normalitas distribusi data iklim kelas dan resiliensi akademik diketahui bahwa signifikansi $\mathrm{P}=0,656>0,05$ artinya distribusi normal

Uji normalitas distribusi data MGO dan resiliensi akademik diketahui bahwa signifikansi $\mathrm{P}=0,932>$ 0,05 artinya distribusi normal. Uji normalitas distribusi data MGO dan prestasi belajar diketahui bahwa signifikansi $\mathrm{P}=0,595>0,05$ artinya distribusi normal. Uji normalitas distribusi data resiliensi akademik dan prestasi belajar diketahui bahwa signifikansi $\mathrm{P}=0,595>0,05$ artinya distribusi normal. Dalam uji korelasi, Nisfianoor (2013) menyatakan bahwa data penelitian harus bersifat linear agar data tersebut dapat diuji secara korelasional.

Uji linearitas iklim kelas dan prestasi belajar diketahui bahwa nilai $\mathrm{p}=0,850>0,05$, jadi data linear. Uji linearitas iklim kelas dan MGO diketahui $\mathrm{P}=0,633>0,05$ artinya data linear. Uji linearitas iklim kelas dan resiliensi akademik diketaui $\mathrm{P}=0,873>0,05$ artinya data linear. Uji linearitas resiliensi akademik dan prestasi belajar diketahui $\mathrm{P}=0,723>0,05$ artinya data linear. Uji linearitas MGO dan prestasi belajar diketahui $\mathrm{p}=0,808>0,05$ data linear. Uji Linearitas resiliensi akademik dan MGO diketahui $\mathrm{P}=0,894>$ 0,05 artinya data linear.

Uji korelasi dilakukan untuk mengetahui hubungan antara 2 variabel yang digunakan dalam penelitian ini. Diketahui bahwa $r=-0,152$, dan $\operatorname{sig}(\mathrm{P})=0,152>0,01$ artinya tidak ada korelasi antara iklim kelas dengan prestasi belajar. Diketahui bahwa $r=0,526$, dan sig $(p)=0,000<0,01$ artinya ada korelasi yang signifikan antara iklim kelas dengan MGO. Makin tinggi iklim kelas maka makin tinggi pula MGOnya. Makin rendah iklim kelas, maka makin rendah MGO-nya. Uji korelasi iklim kelas dengan resiliensi akademik diketahui bahwa $r=0,264$ dan $p=0,012<0,05$ artinya bahwa ada hubungan yang signifikan antara iklim kelas dengan resiliensi akademik. Makin tinggi iklim kelas, maka makin tinggi pula resiliensi akademiknya. Makin rendah iklim kelas, maka makin rendah pula resiliensi akademiknya. Diketahui bahwa $r=0,082, p=0,444>0,05$ artinya tidak ada korelasi antara MGO dengan prestasi belajar. Diketahui bahwa $r=0,026$, dan $p=0,808<0,05$, artinya tidak ada korelasi antara resiliensi akademik dengan prestasi belajar. Ditemukan bahwa $r=.456$ dan $p=0,000<0,01$ artinya ada hubungan signifikan antara MGO dengan resiliensi akademik. Makin tinggi MGO, makin tinggi pula resiliensi akademiknya. Makin rendah MGO, maka makin rendah resiliensi akademiknya. 
Di bawah ini dicantumkan hasil uji regresi terhadap variable-variabel penelitian. Diketahui bahwa $t=$ $-1,446$ dan Sig $(p)=000<0,01$ artinya tidak ada pengaruh iklim kelas terhadap prestasi belajar. Diketahui bahwa $t=5,827$ dan sig $(p)=0,000<0,01$. Jadi terdapat pengaruh yang signifikan iklim kelas terhadap MGO. Dengan r square = 0,276. artinya ada pengaruh 27,6 persen iklim kelas terhadap MGO dan ada faktor-faktor lain yang berpengaruh terhadap MGO. Diketahui bahwa $t=2.569$ dan $\operatorname{sig}(p)=0,000<0,01$ artinya terdapat pengaruh iklim kelas terhadap resiliensi akademik. Adapun $\mathrm{r}$ square $=0$, 070, artinya ada pengaruh sebesar $7 \%$ iklim kelas terhadap resiliensi akademik dan ada faktor-faktor lain sebesar 93 $\%$ yang berpengaruh terhadap resiliensi akademik. Diketahui bahwa $t=0,769$ dan $\mathrm{p}=000<0,01$ artinya tidak terdapat pengaruh MGO terhadap prestasi belajar. Diketahui bahwa $t=0,243$ dan $\operatorname{sig}(\mathrm{p})=0,000<$ 0,01 artinya tidak terdapat pengaruh MGO terhadap Prestasi Belajar.

Regresi antara resiliensi akademik terhadap MGO: Diketahui bahwa $t=4.803$ dan $\operatorname{sig}(\mathrm{p})=0,000<$ 0,01 artinya ada pengaruh signifikan resiliensi akademik terhadap MGO. Adapun r square =0, 208 artinya ada pengaruh sebesar 20,8 persen resiliensi akademik terhadap MGO dan masih ada sebesar 79,2 persen faktor-faktor lain yang mempengaruhi terhadap MGO. Regresi ganda iklim kelas, MGO dan resiliensi akademik terhadap prestasi belajar. Diketahui bahwa $\mathrm{f}=1.819 \mathrm{dan}$ sig $(\mathrm{p})=0,150>0,05$ artinya tidak terdapat pengaruh iklim kelas, MGO, dan resiliensi akademik terhadap prestasi belajar. Secara bersamasama iklim kelas, MGO dan resiliensi akademik tidak berpengaruh terhadap prestasi belajar.

Dalam konteks pendidikan, ternyata bahwa iklim kelas tidak berpengaruh terhadap prestasi belajar. Hasil penelitian ini berbeda dari hasil penelitian Dariyo (2008) yang menyatakan bahwa ada pengaruh iklim kelas terhadap prestasi belajar. Iklim kelas memberikan suasana pembelajaran yang kondusif bagi mahasiswa, sehingga mahasiswa terdorong untuk menguasai materi pelajaran, akhirnya mahasiswa mampu menghadapi tugas-tugas ujian dengan baik.

Selain itu, juga dari penelitian diketahui bahwa resiliensi akademik dan MGO tidak berpengaruh terhadap prestasi belajar. Hasil penelitian ini tidak sejalan dengan hasil penelitian Dariyo (2008) yang menyatakan MGO berpengaruh terhadap prestasi belajar. Rupanya, meskipun seseorang menguasai materi pelajaran, namun bukan berarti ia akan sukses meraih prestasi belajar dengan baik. Ada faktor-faktor lain yang mempunyai hubungan (pengaruh) terhadap prestasi belajar, misalnya: inteligensi (Dalyono, dalam Dariyo, 2013).

Namun demikian ditemukan bahwa iklim kelas yang kondusif memiliki pengaruh signifikan terhadap MGO. Demukian juga, iklim kelas memiliki pengaruh pada resiliensi akademik. Selain itu, ditemukan pengaruh dan hubungan signifikan MGO dengan resiliensi akademik. Hasil-hasil penelitian ini mendukung hasil penelitian Dariyo (2008).

Iklim kelas ialah suasana psikososial yang diciptakan oleh seorang dosen (guru) ketika ia mengajar dalam kelas (Ames, 1992). Suasana psikososial melibatkan hubungan interaksi sosial antara dosen - mahasiswa yang mewarnai konteks pengajaran di kelas (Church, Elliot \& Gable, 2001). Dalam menciptakan iklim kelas, seorang dosen membuat norma-norma yang dijadikan aturan kegiatan perkuliahan. Dosen juga merancang kegiatan perkuliahan, tugas-tugas, ujian maupun evaluasi pembelajaran. Semuanya dikemukakan secara tertulis dalam silabus (SAP - Satuan Acara Perkuliahan) dan bahkan dikatakan secara langsung di hadapan mahasiswa. Pemahaman dan penerimaan mahasiswa terhadap suasana kelas yang diciptakan oleh dosen tersebut, memberi pengaruh positif bagi pembelajaran mahasiswa (Ames, 1992). Suasana kelas yang kondusif tersebut akan mendorong para mahasiswa untuk merasa termotivasi belajar lebih giat agar mereka dapat menguasai materi perkuliahan. Suatu dorongan yang menggerakkan seorang mahasiswa untuk menguasai materi perkuliahan dinamakan mastery goal orientation (Church, et al, 2001). Hal ini sesuai dengan hasil penelitian ini bahwa ada hubungan antara iklim kelas dengan MGO pada mahasiswa.

Seseorang yang memiliki MGO yang tinggi ditandai dengan upaya aktif untuk menguasai materi perkuliahan dengan baik. Ia tidak akan putus asa, menyerah atau berhenti di tengah jalan, jika ia menghadapi kesulitan. Ia menganggap suatu kesulitan sebagai tantangan yang membuatnya untuk terus berpikir positif guna mengatasi kesulitan tersebut. Ia akan berusaha menggunakan berbagai strategi, cara atau metode yang mendorongnya untuk benar-benar menguasai materi dengan baik (Harackiewics, Baron, Tauer \& Elliot, 2002). Namun demikian, motivasi untuk menguasai materi perkuliahan tidak mempunyai hubungan dengan prestasi belajar. Jadi motivasi saja tidak cukup menjamin keberhasilan seseorang dalam mencapai prestasi belajar. Dengan demikian hasil penelitian ini berbeda dengan pandangan Dalyono (dalam Dariyo, 2012) yang mengatakan bahwa motivasi belajar sebagai salah satu faktor yang mempengaruhi prestasi belajar. Padahal masih ada faktor lain yang berpengaruh terhadap prestasi belajar yaitu inteligensi. Dengan 
kecerdasan tinggi, maka seseorang akan bisa meraih prestasi tinggi dalam belajarnya.

Menurut McGregor \& Elliot (2002) seorang mahasiswa yang memiliki MGO yang baik, seharusnya mampu mengembangkan resiliensi akademik. Resiliensi akademik dapat membantu individu dalam menghadapi berbagai persoalan akademik dalam lingkungan pendidikan. Orang yang memiliki ketangguhan akademik ditandai dengan daya juang, tekun, dan sabar dalam menyelesaikan masalah akademik. Karena itu, seseorang akan berupaya keras mengatasi kesulitan-kesulitan dan memanfaatkan berbagai metode, cara atau teknik untuk menguasai materi perkuliahan (Lapper, Corpus \& Iyengar, 2005). Namun demikian, resiliensi akademik saja bukan jaminan bagi seseorang untuk bisa berhasil meraih prestasi belajar yang tinggi, kalau tidak disertai dengan kemampuan akademik yang memadai.

\section{Penutup}

Dari hasil penelitian diperoleh kesimpulan tidak ada pengaruh iklim kelas, resiliensi akademik, dan MGO terhadap prestasi belajar. Namun ada pengaruh signifikan iklim kelas terhadap resiliensi akademik dan MGO, dan juga ada pengaruh antara MGO dengan resiliensi akademik. Dalam penelitian ini iklim kelas, resiliensi akademik dan MGO tidak mempunyai pengaruh terhadap prestasi belajar. Peneliti menduga bahwa hal ini terkait dengan masalah alat ukur penelitian. Alat ukur iklim kelas, resiliensi akademik, dan MGO mempunyai jumlah item lebih sedikit, sehingga berpengaruh dengan jumlah skor setiap skor total masing-masing variabel tersebut. Perbedaan total skor tersebut kemungkinan berpengaruh terhadap proses analisis data kuantitatif (korelasi dan regresi). Karena itu, disarankan bagi penelitian berikutnya untuk memperbaiki alat ukur iklim kelas, resiliensi akademik, dan MGO dengan jumlah item yang memadai sehingga diperoleh skor total yang seimbang dengan nilai prestasi akademik. Selain itu, peneliti menyarankan agar penelitian selanjutnya perlu untuk melibatkan variabel penelitian lain yaitu inteligensi, atau keterlibatan akademik (academic engagement).

\section{Daftar Pustaka}

Ames, C. (1992). Classrooms, Goals, Structures, and Student Motivation. Journal of Educational Psychology, 84 (3), 261-271.

Arbona, C. (2000). The Development of Academic Achievement in School Age Children: Pre Curses to Career Development. In S.D. Brown \& R. W. Lent (eds), Handbook of Counseling Psychology (pp.270-309). New York: John Wiley \& Sons.

Bandura, A. (1997). Self-Efficacy: The Exercise of Control. New York: WH Freeman Company.

Chemers, M. M, Hu, Li-tze \& Garcia, B. F (2001). Academic Self-Efficacy and First-Year College Student Performance and Adjustment. Journal of Educational Psychology, Vol. 93, 55-64.

Church, M. A, Elliot, A.J \& Gable, S.L (2001). Perceptions of classroom environment, Achievement Goals and Achievement Outcomes. Journal of Educational Psychology. Vol.93, No.43-54.

Corsini, R. (2002). The Dictionary of Psychology. London: Brunner/Mazel.

Dariyo, A. (2008). Pengaruh Iklim Lingkungan Kelas, Mastery Goal Orientation, dan Akademik Self-Efficacy terhadap Prestasi Belajar. (tesis, tidak diterbitkan). Jakarta: Program Studi Magister Psikologi Universitas Tarumanagara.

Dariyo, A. (2012). Dasar-dasar Pedagogi Modern. Jakarta: Indeks.

Elliot, A. J. (2005). A Conceptual History of the Achievement Goal Costruct. In A. J. Elliot \& C.S. Dweck, Handbook of Competence and Motivation, pp.52-72. New York: The Guilford Press.

Finn, J. D, Garber, S. B \& Boyd-Zaharias, J (2005). Small-Classes in the Early: Academic Achievement and Graduating From High School. Journal of Educational Psychology, Vol. 97, No.2, 214-223.

Gentry, M, Gable, R, K \& Rizza, M. G. (2002). Students' Perception of Classroom Activities: Are There Grade-Level and Gender Differences ?. Journal of Educational Psychology, 94 (3), 539-544.

Hamachek, D.(1990). Psychology in Teaching, Learning and Growth. (4th edition). Boston: Allyn and Bacon. Harackiewics, J. M, Barron, K. E \& Elliot, A. J. ( 2000). Short-Term and Long-Term Consequences of Achievement Goals: Predicting Interest and Performance Over Time. Journal of Educational Psychology, Vol. 92, No.2, p.316-330.

Harackiewics, J. M, Barron, K. E, Tauer, J. M \& Elliot, J. A. (2002). Predicting Success in College: A Longitudinal Study of Achievement Goals and Ability Measures as Predictor of Interest and Performance From Freshman Year Through Graduation. Journal of Educational Psychology, Vol.94.No.3, p.562- 
575.

Harackiewics, J. M, Barron, K. E, Pintrich, P. R, Elliot, A.J \& Thrash, T.M (2002). Revision od Achievement Goal Theory: Necessary and Illuminating. Journal of Educational Psychology, Vol.94, p.638-645.

Klassen, R. M. (2004). A Cross-Cultural Investigation of the Efficacy of South Asian Immigrant and Anglo Canadian Nonimmigrant Early Adolescence. Journal of Educational Psychology, Vol.96, no. 4, 731742 .

Lapper, M. R, Corpus, J. H \& Iyengar, S. I. (2005). Intrinsic and Extrinsic Motivational Orientation in the Classroom: Age Differences and Academic Correlates. . Journal of Educational Psychology, Vol.97, No.2, 184-196.

Locke, E. A \& Latham, G. P (1990). A Theory of Goal Setting \& Task Performance. New Jersey, Englewood Cliffs: Prentice Hall.

Lodewyk, K. R \& Winne, R. H. (2005). Relationship Among the Structure of Learning Tasks, Achievement and Change in Self-Efficacy in Secondary Student. Journal of Educational Psychology, Vol.97, No.1, 3-12.

Mason, E, J \& Bramble, W. J. (1997). Research in Education and Behavioral science: Concepts and Methods. Madison: Brown \& Benchmark.

McGregor \& Elliot, (2002) Achievement Goals as Predictors of Achievement-Relevant Processes Prior to Task Engangement. Journal of Educational Psychology, Vol.94, No.2, p.381-395.

Nisfianoor (2013). Pendekatan Statistika Modern : Aplikasi dengan Software SPSS dan E-Views. Jakarta: Universitas Trisakti.

Parkay, F.W \& Stanford, B. H.(1995). Becoming a Teacher. (3rd Edition). Boston:Allyn and Bacon. Santrock, J. W. (2008). Educational Psychology. (3rd edition). Boston: McGraw-Hill. 